\title{
内歯車歯面のラッピング仕上げ*
}

中江道彦 ${ }^{* 1}$, 森川浩次 ${ }^{* 1}$, 日高一憲 ${ }^{* 2}$, 取違典嗣 ${ }^{* 3}$, 斎藤一郎 ${ }^{* 3}$

\section{Tooth flank finishing of internal gears with lapping}

\author{
Masahiko NAKAE ${ }^{* 1}$, Hiroshi Morikawa, Kazunori HIDAKA, \\ Tenji TORII and Ichiro Saitou \\ ${ }^{* 1}$ Sasebo National College of Technology. Dept. of Mechanical Engineering \\ Okishin-cho 1-1, Sasebo-shi, Nagasaki, 857-1193 Japan
}

The objective of this research is to develop a gear lapping machine which can simultaneously make all tooth flanks of an internal gear smooth in a short time. A work gear is meshing with two lap gears as crossed helical gears and supported by a guide gear during the lapping. The two lap gears and the guide gear are made of nylon. Lapping slurry containing abrasive grains is supplied to the meshing teeth. The structure of the lapping machine designed and manufactured by the authors is shown. The work gears are lapped using lap gears which have tooth trace modified based on the calculated results to prevent the interference. They are evaluated with regard to the tooth roughness and the accuracy of the tooth profile. The results are as follows. (1) A work gear meshed with lap gears without the occurrence of the interference. (2) Tooth flanks of work gears were finished smooth as a maximum peak-valley height ( $\mathrm{Rz}$ ) of less than $1 \mu \mathrm{m}$ by this process. (3) It is necessary to enable to finish in shorter lapping time.

Key Words : Gear, Lapping, Internal gear, Abrasive grain, Nylon lap, Surface roughness, Tooth profile

\section{1. 緒言}

内歯車は遊星歯車減速機やギヤカップリングなどに多く用いられている. 多くの利点がある一方，一般的に外 歯車に比べて形状寸法上の制約が多いために加工が困難である．そのため，比較的小径の内歯車を対象とした仕 上げ用加工機は少なく, ギヤシェーパやブローチを用いた歯切り加工の後に熱処理を行い, 精密な仕上げ加工を 施すことなく使用されることが多い.

そこで著者らは，近年開発された内歯車用研削盤(1)やシェービング盤(2)よりも簡便な内歯車歯面仕上げ機の開 発を目的として研究を行っている．これまでに開発した外歯車歯面仕上げ用ラッピング盤(3)と同様の手法を用い て基準ピッチ円径 100～200mm 程度の小径内歯車を対象とし，形状精度を低下させることなく歯面を $1 \mu \mathrm{mRz}$ 以下まで滑らかに能率よく仕上げることを目標として，ラッピング盤を試作し，加工実験を行った．以下に加工 法，ラッピング盤の構造，ラップ歯車形状および実験結果について報告する.

\section{2. ラッピング法および試作ラッピング盤の構造}

本ラッピング法では，ナイロン製の駆動ラップ歯車およびブレーキラップ歯車をワーク歯車とかみ合わせて回 転させる，ねじ歯車の状態でかみ合っている両ラップ歯車歯面には，歯形，歯すじ両方向にすべりが生じる上に ブレーキラップ歯車軸のブレーキによって歯面に荷重が作用するため，砥粒を介在させることにより除去作用が 行われ，ワーク歯車両歯面が同時に仕上げられる. その際，ワーク歯車に上向きの力が作用するのでガイド歯車

\footnotetext{
*1 正員, 佐世保工業高等専門学校（勇857-1193 長崎県佐世保市沖新町 1-1）

*2 正員, (株)明和製作所 (广819-1106 福岡県系島市志登 130-1)

*3 株カシフジ(T601-8131 京都市南区上鳥羽鴨田 28)

E-mail:nakae@sasebo.ac.jp
}

一般社団法人 日本機械学会 [No.13-17] MPT2013 シンポジウムく伝動装置〉講演論文集 [2013.11.14ー16, 宮崎] 
Table 1 Specifications of gears

\begin{tabular}{|l|l|c|c|}
\hline & Work gear & Lap gear & Guide gear \\
\hline Type & Helical internal & Spur & Helical \\
\hline Module & \multicolumn{3}{|c|}{1.55} \\
\hline Number of teeth & 70 & 36 & 19 \\
\hline Helix angle deg & $27.0(\mathrm{LH})$ & 0 & 27.0 (LH) \\
\hline Pressure angle deg & & 20 \\
\hline Tooth depth mm & 3.0 & \multicolumn{2}{|c|}{3.805} \\
\hline Face width mm & 20 & \multicolumn{2}{|c|}{40} \\
\hline Material & $\begin{array}{l}\text { JIS SCM420 } \\
\text { (56-60HRC) }\end{array}$ & \multicolumn{3}{|c|}{ MC nylon } \\
\hline
\end{tabular}

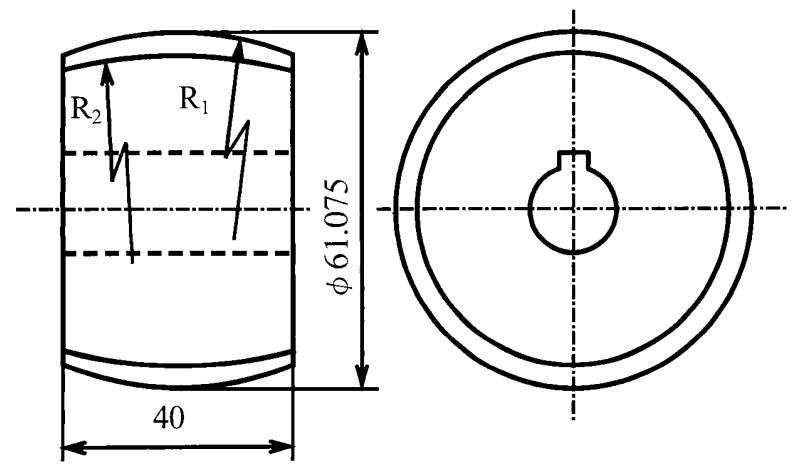

$\mathrm{R}_{1}=52:$ Radius of curvature of tooth crest

$\mathrm{R}_{2}=81$ : Radius of curvature of bottom land

(a) The shape

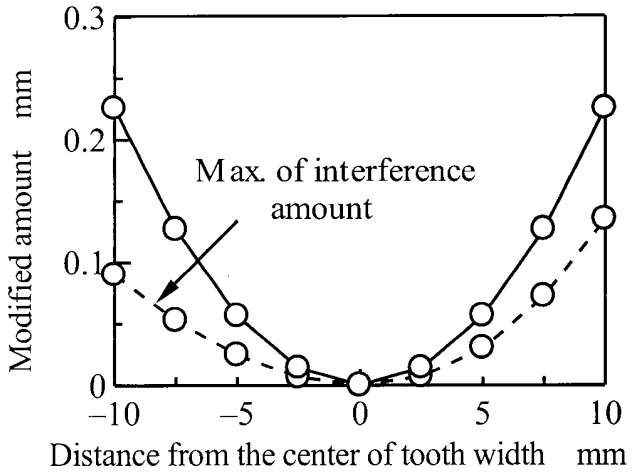

(b) Modified amounts on tooth trace

Fig.1 Shape and modification amounts of a lap gear

によって支える，また，ワーク歯車は両側面をそれぞれ 4 個の回転リングで支持し，送り装置によって歯幅方向 に往復運動を与えて歯面全体を加工する. 表 1 に本研究で用いるワーク歯車, ラップ歯車およびガイド歯車の諸 元を示す. 試作したラッピング盤はベッド, 主軸台を備えた 2 つコラム, ガイド歯車台, ワーク歯車保持装置, 往復送り装置およびラップ剂供給装置から構成される。

\section{3. ラップ歯車の形状}

ワーク歯車がはすば内歯車であるからラップ歯車を標準平歯車とすれば両歯車のかみ合いにおいて歯面間に干 渉が生じる．そこで両歯車の歯形輪郭座標を求めて干渉量を計算し，その結果を考慮して干渉を避けるように歯 すじを修整したラップ歯車（I）を製作した．図１にそその形状および歯幅方向各位置の歯すじ修整量を示す．外 形もワーク歯車と干渉しないように樽型とした。

\section{4. 加工実験}

\section{$4 \cdot 1$ 実験方法および条件}

ブローチによる歯切り後に浸炭焼入れを施した内歯車をワーク歯車とし，上記のラッピング盤㧍よびラップ歯 車を用いて加工実験を行った. ラッピング前および4〜8 ストローク加工毎にワーク歯車の質量, 歯面粗さ, 歯形 䛊差, 歯すじ誤差を測定し, 除去量, ワーク歯車の歯面粗さ・形状精度の変化を調べた. ラップ剂は砥粒 (WA500,WA1000) $5 \mathrm{~g}$ に対してラッピングオイル（動粘度 $4.7 \mathrm{~mm}^{2} / \mathrm{s}$ ） $200 \mathrm{~cm}^{3}$ の割合で混ぜたものを使用し，滴下 量は約 $17 \mathrm{~g} / \mathrm{min}$ とした. 駆動ラップ歯車回転速度 n $2000,2500 \mathrm{~min}^{-1}$, 送り速度 $\mathrm{f} 5,7.5,10 \mathrm{~mm} / \mathrm{s}$, ブレーキトルク $\mathrm{T}$ $330,495,660 \mathrm{Nmm}($ ワーク歯車ピッチ円上円周荷重 $11.8,17.7,23.6 \mathrm{~N})$, ストローク $20.5 \mathrm{~mm}$, 軸交差角 $27.5^{\circ}$ とした. 


\section{4・2 実験結果および考察}

\section{4・2・1 砥粒粒度による除去量および歯面粗さの比較}

図 2(a)(b) は砥粒 WA500 および WA1000 を用いて回転速度 $2000 \mathrm{~min}^{-1}$, 送り速度 $\mathrm{f} 5 \mathrm{~mm} / \mathrm{s}$ ，トルク $\mathrm{T} 495 \mathrm{Nmm}$ の 条件の下でラッピングした時のワーク歯車の除去量および歯形方向歯面粗さの推移を比較したものである. 図(a) よりいずれの砥粒の場合も除去量は直線的に増加しているが，WA500 の方が単位時間当たりの量は 2 倍程多い ことがわかる．図(b)より，WA500 は急激に歯面粗さを減少させるが， $1 \mu \mathrm{mRz}$ 程度に達してからは減少しなくな る. それに対し，WA1000 は時間を要するが，WA500 よりも歯面粗さを減少させ，歯形方向歯面粗さを $1 \mu \mathrm{mRz}$ 以下にすることができる.

この加工における歯形誤差および歯すじ誤差の推移を示したのが図 3(a)(b)である. 両図より加工時間が 100 秒以上になると誤差が増加する傾向が見られ，特にWA500ではより増加しや寸いことがわかる.

\section{$4 \cdot 2 \cdot 2$ 加工条件による歯面粗さ低隇の比較}

ワーク歯車の精度低下を防止するためにもできるだけ短時間にラッピング仕上げを終了する必要があるそそこ で, 砥粒 WA500 を用い, 各種条件の下で 100 秒閒ラッピングを行い, ワーク歯車の歯面粗さの推移を比較した. 図 4(a)〜(c)はそれぞれ送り速度，トルク（加工負荷）および回転速度の影響を示したものである. 図(a)から送り

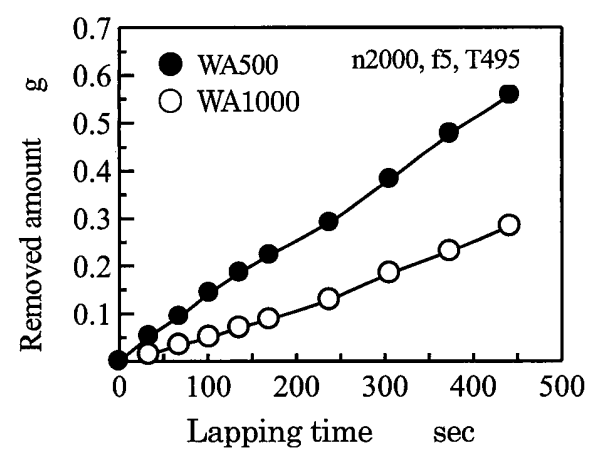

(a) Amounts of removed mass

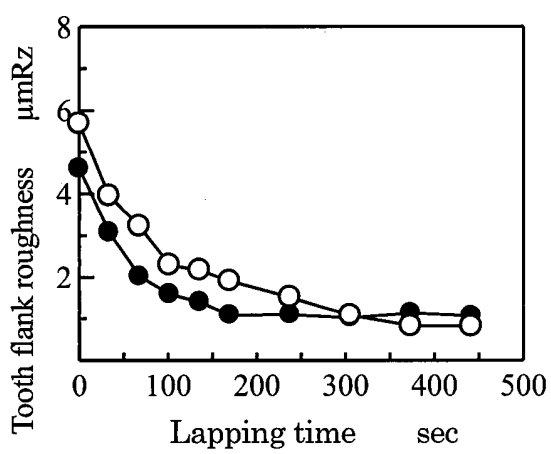

(b)Tooth flank roughness

Fig.2 Effect of size of abrasive grain

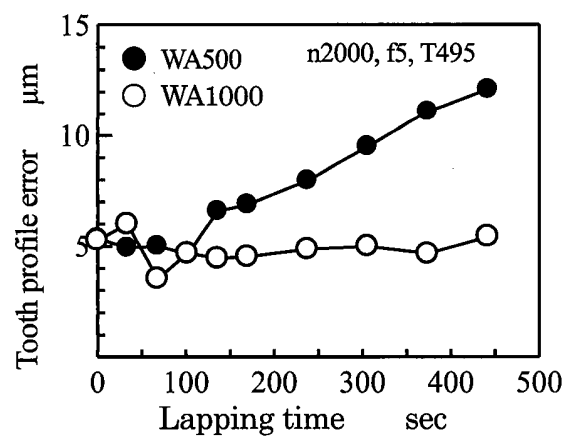

(a) Tooth profile error

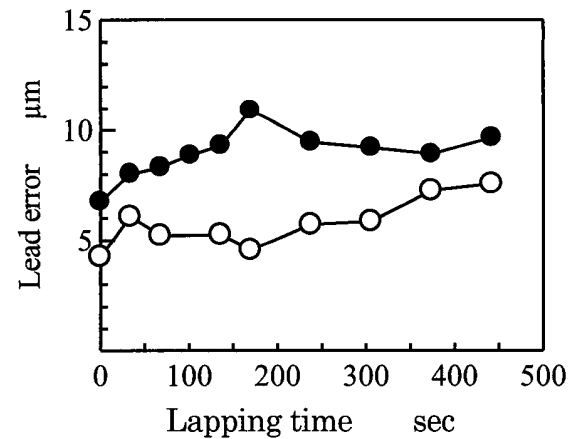

(b)Lead error

Fig.3 Effect of size of abrasive grain

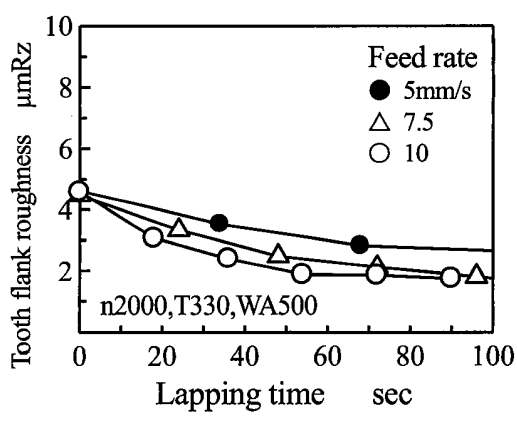

(a) Effect of feed rate

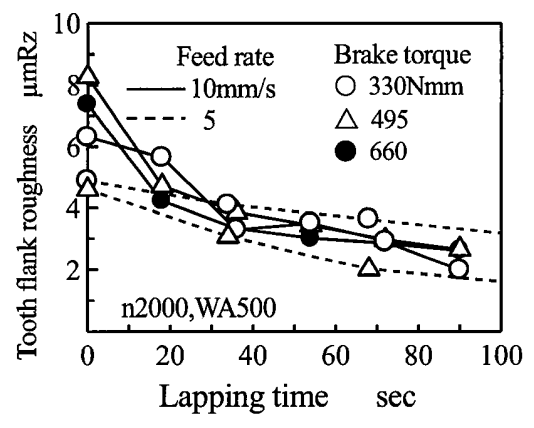

(b) Effect of brake torque

Fig.4 Effect of lapping conditions on tooth flank roughness

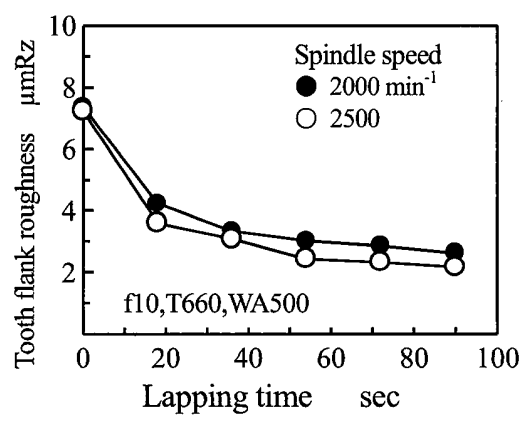

(c) Effect of spindle speed 


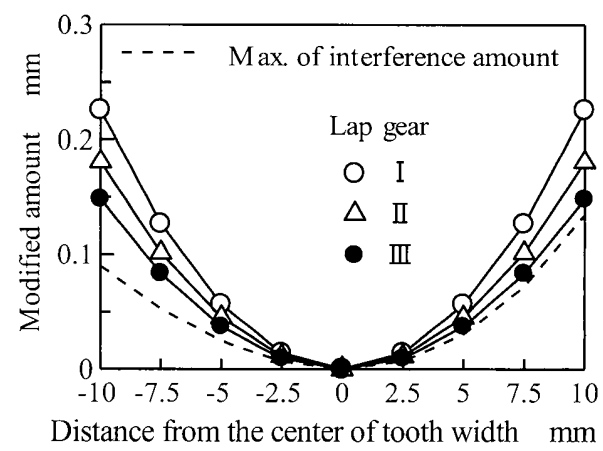

Fig. 5 Modified amounts on tooth trace of lap gears

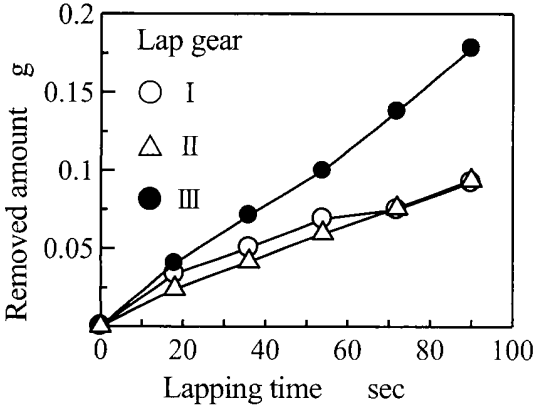

(a) Amounts of removed mass

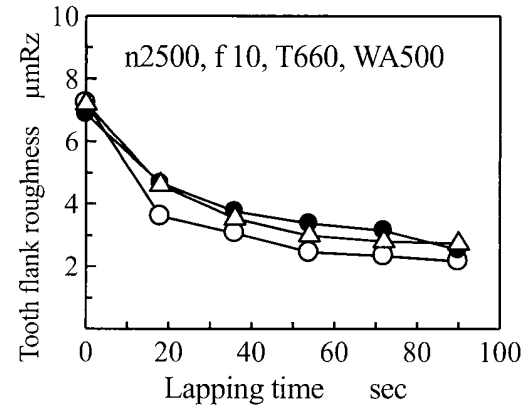

(b) Tooth flank roughness

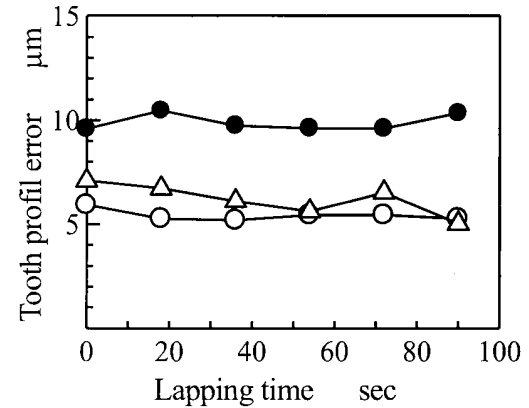

(c) Tooth profile error

Fig.6 Effect of modified amount of lap gears

速度が大きくなるにつれて粗さは減少しやすくなることがわかる. 図(b)からいずれの送りにおいてもトルクは大 きい方が粗さは減少しやすいことがわかる．図(c)の回転速度も大きい方が粗さはより小さくなりやすい.

\section{$4 \cdot 2 \cdot 3$ ラップ歯車歯すじ修整量の影響}

以上の実験では比較的大きな菊すじ修整量をもつラップ歯車（I ）を用いたが，図 $1(\mathrm{a})$ の歯底円曲率半径 $\mathrm{R}_{2}$ を 101 および 123 に変更して図 5 に示すように修整量を小さくし, ワーク歯車歯面との接触領域が大きくなるよ うにしたラップ歯車（II，III）を用いた場合の影響を調べた. 図 6(a)〜(c)は各ラップ歯車による除去量, 歯面粗 さおよび歯形誤差の推移を比較したものである．除去量はラップ歯車而の場合が大きいが，歯面粗さについては ラップ歯車 I の方が減少しやすい，歯形誤差はいずれの場合も加工前の精度とほとんど変わらない．

\section{5. 結 言}

以上から次のことがわかった。

（1）計算によって求めた干渉量より大きな歯すじ修整を施したラップ歯車を用いれば，干渉を起こすことなく ワーク歯車とかみ合い，浸炭焼入れした内菌車の歯面粗さを $1 \mu \mathrm{mRz}$ 以下に仕上げることができる.

(2) 歯すじ修整量の大きいラップ歯車の方が歯面粗さを減少させやすい.

(3) ワーク歯車の精度低下を生じさせないために, 適切な条件の下でできるだけ短時間に仕上げられるような 手段を検討する必要がある。

\section{文献}

（1）桝瀬吉言, 越智政志, 中路慶弘, 西村幸久, 芹沢祐二, “世界初量産用内歯車研削盤 ZI120A の開発”, 三菱重工技 報, Vol.46,No.3(2009), pp.7-11.

(2) 小林 慶紀, “内歯車の仕上げ加工「インターナルシェービング加エシステム」”, 不二越テクニカルレポート, Vol.21B1(2010),pp.1-7.

(3) Nakae, M., Hidaka, K., Morikawa, H., Torii, T., and Sao, S., " Development of the Center-Less Gear Lapping Machine and the Lapped Gears", Journal of Advanced Mechanical Design, Systems, and Manufacturing, Vol.5, No.3, 2011, pp.160-170. 